\title{
Reflexões sobre a noção de transição na ação do ator
}

\author{
Maria Paula Carvalho Bonilha*
}

Este artigo busca a definição da noção de transição como elemento constituinte da ação física do ator. $\mathrm{O}$ marco referencial deste estudo define a via física como eixo para o trabalho criativo do ator. Com o Método das Ações Físicas de Stanislavski ${ }^{1}$ ocorre um deslocamento no foco de entendimento e tratamento da ação, até então empregada sobretudo a partir de processos psicológicos, como o da visualização das situações fictícias e a conseqüente internalização dos seus desdobramentos no corpo.

O entendimento da falsa cisão entre corpo/mente na experiência laboratorial de encenadores como Meyerhold, Grotowski e Barba - em simultaneidade ao reconhecimento do caráter psicofísico da ação - tornou-se um estímulo constante às gerações subseqüentes, empenhadas na codificação de técnicas para a elaboração da ação que apostam na via física como motor criativo do ator.

Investigar a ação sob este ponto de vista propõe que o ator engatilhe prioritariamente a criação de suas ações físicas e que, a partir delas, o acionamento de mecanismos interiores encontre o justo caminho de encaixe, preenchimento e diálogo com a expressão visível ou o desenho das ações no espaço-tempo.

As reflexões aqui compiladas ${ }^{2}$ têm apontado para a verificação da dimensão psicofísica da ação enquanto viabilizadora do algo mais grotowskiano. Ao diferenciar ação de atividades, gestos e movimentos, o encenador polonês a define como "algo mais porque nasce do interno do corpo, está radicada na coluna vertebral e habita o corpo” (GROTOWSKI, 1988).

Partindo da definição acima, nomeio como textos corporais o conjunto de materiais ${ }^{3}$ relativos às atividades físicas, gestos ou movimentos produzidos pelo ator, não classificados por Grotowski como ação. A noção de texto corporal ancora-se aqui à elaboração de Pavis para texto espetacular, definido como um somatório de todos os sistemas significantes ${ }^{4}$ utilizados na representação e que, arranjados e interagindo-se entre si, compõem a encenação (PAVIS, 1999: 408).

Utilizo, então, a expressão texto corporal para englobar o conjunto de signos produzidos pelo ator capazes de produzir significados e sentidos em seu próprio corpo, como também no corpo-mente do espectador.

\section{Níveis de organização do ator}

Em cena, o ator precisa equacionar duas instâncias de criação. Uma exterior, que pode ser apontada como nível de organização externo, em que o público apreende o desenho

\footnotetext{
* Atriz, diretora, jornalista e professora da rede pública de Florianópolis, cursa o Programa de Pós-Graduação em Teatro (PPGT) da Universidade do Estado de Santa Catarina (Udesc).
} 
visível das ações da personagem e outra interior, ou nível de organização interno, em que o ator formula seu eixo de sustentação e as justificativas internas para suas ações.

$\mathrm{O}$ ator se depara concretamente com a tarefa de executar ações e lidar com os seus níveis de organização. E mais do que isso, se fazer crer para o público e para si. A ação que mobiliza de maneira integral o corpo físico do ator envolve níveis de elaboração que extrapolam a sua condição meramente física, para englobar a dimensão psicofísica.

Com a teorização e a experimentação da dimensão psicofísica da ação (pós Stanislavski), convencionou-se chamar de orgânico o ator capaz de articular com sucesso seus níveis de organização interno e externo. A organicidade passou a ser compreendida como condição de credibilidade ou aspirada qualidade cultivadas pelo ator.

Na construção de seu bios-cênico e do corpo extracotidiano, o ator desafia-se ao exercício de codificação de sua memória, emoções e sentimentos. Signos abstratos instalados na mente do ator que se transformam em imagens corporais traduzidas em ações físicas. Sentimentos, emoções e sensações são habitantes deste novo corpo, mas necessitam de uma lente de aumento para serem visualizados pelo público. Além de ampliados, estes componentes, aliados ao potencial imaginativo do ator, precisam ser encarnados no corpo físico e transformados em ação.

\section{Pensar em ação}

Eugenio Barba apresenta uma noção do Oriente que dialoga com a idéia de transição proposta neste artigo. Trata-se da expressão jo-há-kyu, reguladora das artes orientais e de diversas formas de teatro clássico japonês como uma espécie de código de vida artístico. Barba a recupera para referir-se às fases nas quais subdivide-se cada ação do ator-bailarino:

"A primeira fase é determinada pela oposição entre uma força que tende a desenvolver-se e outra que a retém (jo: reter); a segunda fase (há: romper, quebrar) é constituída pelo momento em que se libera desta força, até chegar a terceira fase (kyu: rapidez) na qual a ação atinge seu ponto culminante, desdobrando todas as suas forças para depois deterse repentinamente como diante de uma nova resistência, um novo jo pronto para partir" (BARBA, 1994: 55).

Para além de uma descrição técnica dos vetores de força, tensões e ritmos que estruturam as artes orientais, Barba alerta para a especificidade do jo-ha-kyu enquanto um modelo do pensamento e da ação do ator: "Em nível macroscópico é uma clara articulação técnica, mas superado um certo limiar transforma-se num ritmo do pensar" (BARBA, 1994: 103).

Ampliando o entendimento do jo-há-kyu, Barba ressalta que é possível visualizá-lo também como modelo de pensamento ou espécie de embrião-ritmo do pensamento-em-ação. Em oposição à forma externa fixada pelo ator, sua partitura ${ }^{5}$, existe uma subpartitura sempre aberta à improvisação do ator. 
"Não muda a forma; o mesmo desenho de movimentos é executado inventando as numerosas relações entre jo-há-kyu, cada vez como se fosse a primeira"(BARBA, 1994: 104).

Em meio à criação de seus textos corporais, o ator tem inicialmente fragmentos de futuras ações físicas, recortes que necessitam unir-se de forma a produzir significados e justificativas internas completas, numa progressão das forças que permeiam os inumeráveis 'jo-há-kyus' presentes nestes materiais.

Estruturado pelo código oriental yo-há-hyu, o pensamento-em-ação, enquanto elemento da subpartitura do ator parece firmar sua importância como articulador da ação em seus dois níveis (o interno e o externo), e enquanto meio de justificar e preencher de sentidos pessoais os seus textos corporais.

\section{Corpo em trânsito}

Ao retomar o jo-há-kyu enquanto código de vida e como estrutura de pensamento do ator em ação, pode-se obter ainda uma descrição mais acurada de suas fases.

"Jo: a fase do começo, quando a força se põe em funcionamento como se vencesse uma resistência; ha: a fase de transição, ruptura da resistência, desenvolvimento do movimento; kyu: a fase da rapidez, do crescer sem freios até a parada imprevista” (BARBA apud Burnier, 2001: 149).

Ao mesmo tempo em que é vista como quebra da força de oposição inicial (jo), a fase ha guarda o elemento de transição e desenvolvimento principal da ação. Referindo-se ao jo-ha-kyu como cânone infinito, Barba esclarece que cada uma das três fases subdivide-se em'joha-kyus', "de forma que começa-se a falar de um jo do ha, de um ha do kyu, de um kyu do jo, e assim por diante" (BARBA, 1994: 103).

Uma vez que a fase ha pode ser desdobrada inúmeras vezes ao longo dos segmentos que compõem uma única ação, é possível visualizá-la também enquanto elemento de transição em eterno retorno que viabiliza o desenvolvimento da ação global ao longo do seu percurso trifásico (jo-ha-kyu).

Do latim transitione, a palavra transição é definida como "ato ou efeito de transitar; trajeto, trajetória; passagem de um lugar, de um assunto, de um tom, de um tratamento, para outro". Já o verbo transitar relaciona-se a "fazer o caminho; passar; andar; mudar de lugar, passar por, percorrer” (FERREIRA, 1999: 1987-1988). Emprestando da gramática o significado dos verbos "transitivos", adiciona-se ainda ao termo um valor semântico 'de predicação incompleta e que pedem complemento’ para o entendimento global de seu significado. 
Associando estes conteúdos à fase há do jo-há-kyu observa-se que ela define um trânsito ou um transitar da ação na medida em que o ator percorre o seu caminho, alterando seu estado psicofísico ao longo do tempo-espaço. Por si, a fase de trânsito ha pede um complemento para o fechamento do significado e sentido total da ação, que encerra seu sentido integral em kyu. Por sua vez, a fase kyu, além de fechar o ciclo da ação em seu significado completo, já guarda, em si, o embrião da próxima ação a ser desenvolvida, e assim sucessivamente. "Na realidade, o momento da interrupção (kyu) é uma fase de transição”(BARBA, 1994:103)

Sob o ponto de vista da noção de transição, os textos corporais podem ser visualizados como numa espiral, em que saltos qualitativos fazem com seus limites sejam ampliados a cada giro. Assim, os pontos de saída e de chegada configuram-se como transitórios, como marcas na areia. O que passa a existir é um permanente fluir entre os segmentos (textos corporais) da espiral que se forma. A finalização de um segmento já carrega o embrião em pré-formação do segmento a seguir. Quando o ator encerra uma cadeia coerente de significação de um dado segmento da espiral já elabora indícios do próximo que se configura.

Esta interpretação não pretende engessar ou reduzir o entendimento das fases do código de vida yo-ha-kyu. Ao contrário, reconhece nele o caráter de constante mutação e transitoriedade que caracteriza, nesta leitura, a visualização de uma estrutura mais profunda na ação do ator.

Como descrição de possíveis indicadores da experiência de transição no corpo do ator seleciono duas situações distintas. A primeira ocorre durante uma conferência de Grotowski, em $1988^{6}$. A segunda é registrada em exercício realizado pelo diretor paulista Roberto Mallet. ${ }^{7}$

Comecemos por Grotowski:

Itália, Santo Arcangelo, 1988.

\begin{abstract}
“(...) uma atividade pode se transformar em ação física. Por exemplo, se vocês me colocarem uma pergunta muito embaraçosa (e é quase sempre assim), eu tenho de ganhar tempo. Começo então a preparar meu cachimbo de maneira muito 'sólida'. Neste momento vira ação física, porque isto me serve. Estou realmente muito ocupado em preparar o cachimbo, acender o fogo, assim depois posso responder à pergunta" (GROTOWSKI, 1988).
\end{abstract}

Durante a conferência a Santo Arcangelo, Grotowski se dedica a distinguir ação física de atividades, gestos e movimentos. Para isso, recorre pedagogicamente à demonstração e exemplificação destas diferentes tipologias em seu próprio corpo. No excerto acima, ele utiliza o acenar de uma suposta pergunta embaraçosa do público como estratégia e exemplo didático para demonstrar o que vem a ser ação física à platéia. Ele inicia com a atividade física de preparar o cachimbo e, utilizando o estímulo fictício externo (pergunta do público), vai 
conferindo 'maior solidez' à atividade ao mesmo tempo em que transita para um novo estado definido por ele como ação.

Brasil, Florianópolis, 2000.

Durante a oficina no Ceart, o diretor Roberto Mallet pede para que os atores realizem diferentes atividades, como o lavar louças. Com o passar do tempo, solicita que reajam a sucessivas interferências externas (barulhos variados) que devem estimular alterações dos estados (trânsitos psicofísicos) durante a execução da atividade visando à criação da ação de lavar louças.

Em ambos os casos, as interferências externas (pergunta do público, no caso de Grotowski e ruídos, na experiência de Mallet) durante as atividades estimularam trânsitos psicofísicos nos atores capazes de transformá-las no que Grotowski chama de ação física. Estas interferências provocam mudanças qualitativas ao longo do tempo-espaço, progressivamente, alterando o estado psicofísico do ator e conformando, por cumulação e transformação, outro patamar qualitativo ao conjunto de gestos e movimentos presentes (textos corporais) nas atividades.

Estendendo-se as situações acima à composição da cena, pode-se pensar nos sinais externos como estímulos capazes de provocar trânsitos no corpo-mente do ator. Estes sinais surgem como gatilhos e podem partir de diferentes elementos da encenação. Desde as indicações verbais da direção até a relação com outros atores, o diálogo com a música e a manipulação de objetos.

\section{Trânsitos e níveis de organização}

A partir da verificação da noção de transição presente na ação, pode-se associá-la aos níveis de organização interno e externo, e obter ao menos dois tipos de manifestação no corpo-mente do ator-bailarino.

A primeira é relativa ao trânsito entre um texto corporal e outro - inseridos na seqüência total de materiais de sua partitura. Pode-se classificar este percurso como interacional. Burnier refere-se a ele como ligâmen ou pequeno elemento capaz de ligar as ações físicas entre si na composição do que Stanislavski chamou de linha de ações físicas (Burnier, 2001: 37). A segunda refere-se ao percurso intracional, ou à elaboração da transição como sustentação da ação interna do ator, ou seja, entre os níveis de organização interno e externo do ator num dado segmento de texto corporal.

Ao operar como trânsitos ou percursos entre os textos corporais, as transições interacional e intracional despontam como elementos de ligação em montagens cênicas que utilizam diferentes tipologias de materiais. Para Burnier, estes trânsitos (ligâmens) ${ }^{8}$, são responsáveis pela organicidade da seqüência dos materiais, proporcionando variações relativas a tempo, espaço e nível energético das ações físicas.

No momento em que transita entre atividades, gestos ou movimentos, justificandoos através do acionamento do pensamento-em-ação (e outros mecanismos de ativação da subpartitura), o ator parece acionar de fato, na medida em que produz sentidos em seu 
corpo-mente e possibilita a leitura de sua transformação pelo público. Enquanto lida com estes materiais, o ator encontra na partitura corporal o instrumental para repetir, sistematizar e codificar seus textos corporais.

Com a partitura, o ator é capaz de focar e selecionar as seqüências de textos corporais cujos conteúdos dialoguem com maior precisão as justificativas e sentidos pessoais que empresta à elaboração de cada fragmento. A repetição destes fragmentos faz com que ele enxergue, na seqüência repetida e fixada, um novo trânsito gerador da próxima seqüência, e assim sucessivamente.

\section{Ação transformadora}

Além de mobilizar e habitar integralmente o corpo do ator, a ação também guarda uma eficaz força de transformação do seu estado psicofísico. $O$ ator precisa compartilhar este estado com o público e transformá-lo igualmente, na medida em que o espectador experimenta-se como testemunha privilegiada da cena teatral. A ação do ator parece estar fundada, em essência, numa atitude capaz de modificar a realidade daquele que age (ator) e daquele que o observa (público).

Uma vez optado pela via física como eixo para a criação, o que de fato poderá favorecer a criação deste plano de transformação? O que é capaz de distinguir ação física de outros ‘textos corporais'? Aqui reside o clássico nó do ator frente à administração de sua técnica em equilíbrio, a manutenção de seu corpo-em-vida. Não há respostas fixas nem verdades irrefutáveis. No entanto, a eterna inquietação do artista não impede a tentativa de iluminar estas questões com possíveis leituras...

A construção deste plano de transformação parece acenar para a realização de ações mais consistentes na medida em que desvelam e concretizam, no aqui-agora teatral, as mudanças e contradições impressas em seu corpo-mente. Ao dedicar-se a esta tarefa, o ator intenta trazer para a tessitura de sua ação algo mais consistente, para além do que a narração dramatúrgica ou dos acontecimentos da fábula pode subsidiar.

A ação física encontra na transição um eixo transformador que a eleva à condição de evento cênico singular, tanto para o ator quanto para o público. A percepção desta noção, ainda que diáfana, provoca em ambos o reconhecimento imediato de um singular ocorrido, desdobrado e desvelado pela presença do ator. A transição aponta para a descoberta de uma ação que mobiliza o espectador pela identificação do humano que habita o corpo-mente do ator.

A transição pode ser contemplada em montagens que utilizam diferentes estéticas e procedimentos para a composição de ações físicas. $\mathrm{O}$ ator pode se valer de processos híbridos ou não-convencionais para instalar a ação física e transitar entre elas, justificando-as e apropriando-se delas durante a repetição de suas partituras corporais.

$\mathrm{Na}$ fronteira entre teatro, dança e performance, a noção de transição opera como ponto de encruzilhada no manejar técnico do ator aberto à construção de diferentes poéticas para a cena. Poéticas menos vinculadas ao texto escrito - ou que demandem a criação de novas relações entre ator-texto-cena, em que o corpo constrói seus sentidos e enreda seus discursos 
expressivos ou dramáticos.

Assim como a noção de transição, a articulação do pensamento em ação e a partitura corporal podem ser testados por atores inseridos em diferentes estéticas teatrais, pois pressupõem, em sua base estrutural, a verificação dos níveis básicos de organização da ação do ator: o interno e o externo.

Estas noções operam em diversidade espetacular e são passíveis de reorganização por aqueles que buscam uma elaboração pessoal, uma poética do fazer artístico, através da compreensão de como articulam e disponibilizam seu trabalho em prol da ação e da diversidade da cena.

\section{Apêndice - entendimento da ação do ator após este percurso...}

Ação do ator (a partir da via física) - Evento cênico singular que o ator realiza como seu objetivo imediato, acontece enquanto diálogo legítimo (orgânico) entre vida interna e externa (níveis de organização). Para isso, utiliza, entre outros procedimentos, noções e técnicas de acionamento de pensamento-em-ação e o instrumental da partitura corporal para intentar uma transformação de seus textos corporais. Cada texto corporal funciona como uma célulatrânsito em potencial para o próximo, e assim sucessivamente, de forma que cada texto traz, em si, o germe do seguinte. Ou ainda, o trânsito pode ser contemplado como gestor em potência da ação significativa, aquela que deixou de ser gesto, movimento ou atividade física para se tornar algo mais, ou o evento cênico singular capaz de transformar e envolver ator e público.

Obs.: A transição está nas mãos do ator. Ele se depara com inúmeras possibilidades de criar o próximo texto corporal, mas tem sempre de escolher a via de acesso às sucessivas transformações... Precisa também resistir às idéias brilhantes que despontam no encadeamento dos trânsitos. A opção pela via física impõe sutilezas. Idéias têm que advir da necessidade do corpo. Musculatura, ossos e vísceras ganham espaço na projeção das linhas da ação transformadora com urgente e orgânica necessidade. Só assim o trânsito poderá sustentar, em germe, o encadeamento vital para a próxima ação.

\section{Notas}

1 Já no final de sua vida, Stanislavski iniciou a elaboração do Método de Ações Físicas (durante sua passagem pelo Estúdio de Ópera e a montagem de Tartufo, de Molière) demarcando um momento em que a ação física toma a frente do processo criativo do ator.

${ }^{2}$ Este artigo foi escrito a partir da compilação da monografia de final de curso Ação em Trânsito - uma reflexão sobre a noção de ação no processo de pesquisa do ator, defendida pela autora em 2004, no Centro de Artes (Ceart) da Udesc.

${ }^{3}$ Utilizo a definição de Matteo Bonfito em O Ator Compositor que designa materiais como "qualquer elemento que 
adquire função no processo de construção da identidade do próprio objeto", pp.132-135.

${ }^{4}$ Conforme Pavis, a semiologia teatral concebe o signo como resultado de uma semiósis, ou correlação entre o plano de expressão (significante) e do conteúdo (significado).

${ }^{5}$ Utilizo a noção de Grotowski para partitura, na qual o ator realiza uma série de ações físicas (artifício) para englobar a notação de todos os signos visíveis das ações. A partitura se concebe como uma sucessão de signos (forma) decodificáveis pelo público em dialética complementariedade à vida interior (espiritual), na medida em que revela a inexistência da contradição entre vida interna e artifício criado pelo ator. Noção citada por Patrice Pavis in De Stanislavski a Wilson: antologia portátil sobre a partitura. Tradução de Paolo Dodet anexada em A partitura corporal e o trabalho do ator: conceitos e técnicas aplicativas na composição da cena. Monografia de conclusão de curso de Licenciatura em Artes Cênicas de Monica Siedler. Centro de Artes (Ceart), Universidade do Estado de Santa Catarina, 2003.

${ }^{6}$ A transcrição de parte da Conferência de Grotowski a Santo Arcângelo, em 1988, resultou no importante texto Sobre o Método de Ações Físicas, traduzido por Dinah Kleve, não publicado.

7 As oficinas A Poética da Ação e Ação Poética I e II ocorreram no Centro de Artes (Ceart), em 1999 e 2000.

${ }^{8}$ Burnier classificou os trânsitos como ligâmens de três tipos (simples, compostos ou complexos), subdividindo-os conforme a combinação das coordenadas envolvidas (tempo/espaço/energia vibratória), em evento no Centro de Artes (Ceart) da Universidade do Estado de Santa Catarina (Udesc).

\section{Bibliografia}

BARBA, Eugenio. A canoa de papel. São Paulo: Hucitec, 1994.

BONFITTO, Matteo. O ator compositor. São Paulo: Perspectiva, 2002.

BURNIER, Luís Otávio. A arte do ator: da técnica à representação. Campinas: Editora da Unicamp, 2001.

GROTOWSKI, Jerzy. Em busca do teatro pobre. Rio de Janeiro: Civilização Brasileira,1987.

. Conferência a Santo Arcangelo de 18 de Julho de 1988. Transcrição de gravação, em francês, traduzida por Dinah Kleve. Não publicada, 1988, in A arte secreta do ator. Da técnica à representação. Burnier, Luís Otávio. Campinas: Editora da Unicamp, 2001, pp. 32-33.

PAVIS, Patrice. A análise dos espetáculos. São Paulo: Perspectiva, 2003.

SIEDLER, Monica. A partitura corporal e o trabalho do ator: conceitos e técnicas aplicativas na composição da cena. Florianópolis: Udesc, 2003. Monografia de Conclusão de Curso de Licenciatura em Educação Artística Habilitação em Artes Cênicas. Centro de Artes (Ceart), Universidade do Estado de Santa Catarina (Udesc), 2003. 
Urdimento recomenda os seguintes periódicos ligados às Artes Cênicas:

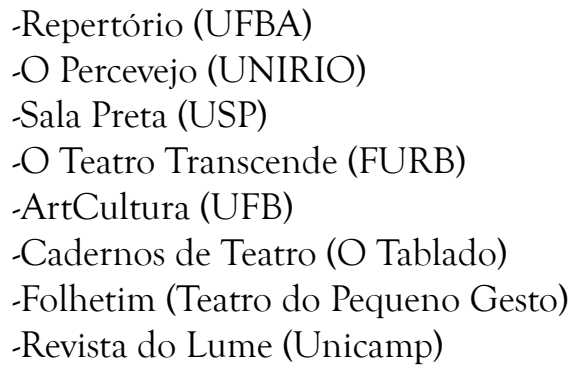




\section{NORMAS PARA PUBLICAÇÃo}

Os artigos encomendados têm prioridade na publicação. As colaborações enviadas espontaneamente são examinadas pelo Conselho Editorial. Em qualquer dos casos, as seguintes normas técnicas devem ser observadas:

1) artigos - mínimo de 8 e máximo de 12 laudas; resenhas de livros, mínimo de 3 e máximo de 4 laudas, digitadas em tipologia 12, Times New Roman, espaçamento normal, Word para Windows (ou compatível), limite de 5700 caracteres com espaços por lauda;

2) solicita-se clareza e objetividade nos títulos;

3) as notas devem ser formatadas em algarismos arábicos, apresentadas ao final do texto. A bibliografia deve ser acrescentada imediatamente após as notas, obedecendo o seguinte padrão: SOBRENOME, Nome, Título (tradutor), Local, Editora, Ano, páginas referidas (ex: 13-16). Para periódicos e jornais: SOBRENOME, Nome, Artigo/Reportagem, Periódico ou Jornal, noV (tradutor), Local, Editora, Ano ou Data, páginas referidas. Periódicos não devem ter títulos abreviados;

4) para indicações de obras no corpo do texto ou final da citação: SOBRENOME, Ano: número da página). Para quaisquer outras normas, seguir o padrão ABNT vigente;

5) no corpo do texto, usar a primeira letra maiúscula e toda(s) a(s) palavra (s) em itálico para nomear títulos de peças, óperas, livros, títulos e obras em geral;

6) as colaborações devem incluir uma brevíssima apresentação do autor, visando situar o leitor, de no máximo 3 linhas;

7) à parte, o colaborador deve enviar uma autorização para publicação. Caso inclua fotos, desenhos ou outros materiais gráficos da autoria de terceiros, é indispensável o aceito dos mesmos assim como uma legenda de identificação;

8) o conjunto destinado à publicação deve ser encaminhado em duas cópias impressas e outra em disquete aos cuidados da revista, até o prazo do fechamento.

Endereço para correspondência e envio de colaborações:

Revista Urdimento

PPG-Teatro - UDESC

Av. Madre Benvenuta, 1907

88035-001 - Itacorubi - Florianópolis - SC

Telefone: (0xx48) 3321-8300

E-mail: urdimento@udesc.br 
Realização:

\section{PPG Teatro}

Programa de

Pós - Graduação

em Teatro

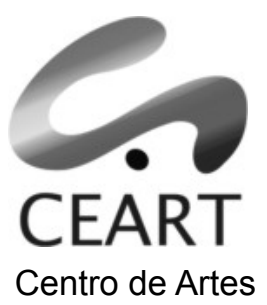


Diagramação Editorial:

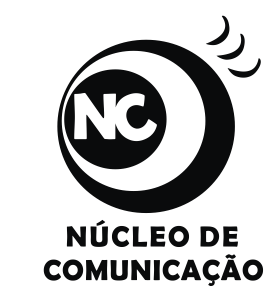

CEART/UDESC

Este projeto editorial foi criado eletronicamente utilizando o software Adobe In Design CS2.

As famílias tipográficas Gouldy Old Style e Britannic Bold são utilizadas em toda esta revista. 